\title{
Research on the Influence of External Audit Characteristics on Selective Disclosure of Internal Control Deficiencies
}

\author{
Fengjiao Long, Wei Liu \\ Fuzhou Melbourne Polytechnic \\ Fuzhou, 350108, China
}

\begin{abstract}
Based on the A-share listed companies on the main board of Shanghai and Shenzhen during the 2014-2016, which have been restated in the financial reports, this paper selected the sample of listed companies with deficiencies in internal control. According to whether the listed company disclosed the internal control deficiencies in the self-evaluation report or not, this paper analyzes the influence of external audit characteristics on selective disclosure of internal control deficiencies. It is found that companies with large audit scale and longer audit tenure are less inclined to disclose internal control deficiencies selectively, and the change of audit firm and non-standard audit opinion of financial report can restrain the selective disclosure of internal control deficiencies.
\end{abstract}

Keywords-internal control deficiencies; selective disclosure; external audit characteristics

\section{INTRODUCTION}

Since "Enterprise Internal Control Basic Standard" and "Enterprise Internal Control Guidelines" were issued in 2008 and 2010, internal control is getting more and more attention in China. However, the performance of listed companies in internal control deficiencies disclosure is unsatisfactory, many listed companies who report no deficiencies in their self-evaluation reports was exposed violations of laws and regulations, punished by CSRC, financial restatements/fraud or other scandals. This means that listed companies disclose internal control deficiencies selectively [1-2].As an important external supervision, can the accounting firm restrain the selective disclosure of internal control deficiencies? Which audit characteristics will affect selective disclosure of the internal control deficiencies? In order to clarify the above problems, this paper selects companies with financial restatements as the sample of internal control deficiencies, examined the impact of audit characteristics on the selective disclosure of internal control deficiencies based on the dimensions of audit scale, auditor change, audit tenure and audit opinions of financial statements.

\section{REVIEW OF LITERATURE AND HYPOTHESIS DEVELOPMENT}

\section{A. Audit Scale and Selective Disclosure of Internal Control Deficiencies}

Krishnan et al. (2007) believe that large and professional accounting firms are stricter in auditing internal control, so they find deficiencies in internal control easily [3]. Xiaolin Chen et al. (2013) find that large accounting firms can improve the quality of information disclosure, small-sized accounting firms with limited professional level may not be able to identify internal control deficiencies, or even help companies to cover up internal control deficiencies for the purpose of retaining customer resources [4]. Therefore, the managers of large accounting firms are less likely to take chances and more inclined to disclose internal control deficiencies voluntarily. Based on the above analysis, this research proposes the following hypothesis:

H1: Companies that hire large accounting firms are less likely to disclose internal control deficiencies selectively.

\section{B. Audit Change and Selective Disclosure of Internal Control Deficiencies}

The accounting firm will assess the audit risk before accepting the business commission. For clients with higher audit risk, accounting firms will choose to abandon the audit business. According to Astibaugh-Skaife et al. (2007)[5] and Ettredge et al.(2011)[6] , listed companies are more likely to disclose internal control deficiencies in the year of audit change. Xiaoke Cheng et al. (2016) find that there is a significant negative correlation between the disclosure of internal control deficiencies and the continued employment of accounting firms, which indicates that the change of accounting firm can improve the possibility of deficiencies disclosure [7]. An audit change is a public signal of internal control deficiencies, and selective disclosure on internal control deficiencies would be easy to arouse suspicion at this point. Therefore, it is more likely that listed companies will disclose internal control deficiencies on its own initiative. Based on the above analysis, this research proposes the following hypothesis:

H2: Companies with audit change are less likely to disclose internal control deficiencies selectively.

\section{Audit Tenure and Selective Disclosure of Internal Control Deficiencies}

Jenkins and Velury (2008)find that the longer the audit tenure, the deeper the auditor knows about the client, and that can effectively restrain the motivation of earnings management, increase accounting conservatism, and play a more significant role as an independent third party supervision [8]. The research of Xiaoke Cheng et al. (2016) shows that the extension of audit tenure could inhibit the motivation of managers from concealing internal control deficiencies [7].Based on the above analysis, this research proposes the following hypothesis: 
H3: Companies with longer audit tenure are less likely to disclose internal control deficiencies selectively.

\section{Audit Opinions of Financial Reports and Selective Disclosure of Internal Control Deficiencies}

The non-standard audit opinion on financial reports indicates that the reliability of the financial reports cannot be guaranteed, and it also indirectly indicates that there are deficiencies in the internal control. In the same financial year, it can be unreasonable if the managers disclose internal control without deficiencies in the self-evaluation report. The empirical research of Baixing $\mathrm{Li}$ and Ruijing $\mathrm{Li}$ (2016) shows that the higher the qualities of financial reports, the less internal control deficiencies the listed companies disclose [9]. Yating Lu (2016) finds that audit opinions of non-standard financial reports can significantly improve the possibility of internal control deficiencies disclosure [10].

H4: Companies with non-standard audit opinion are less likely to disclose internal control deficiencies selectively.

\section{STUDY DESIGN}

\section{A. Sample selection and data sources}

Existing research shows that financial restatements is an important indicator of serious deficiencies in internal control
[11]. In this paper, listed companies with restated financial statements are defined as the sample of serious internal control deficiencies. According to the type of internal control deficiencies disclosed by sample companies, this paper determines the degree of selective disclosure of internal control deficiencies. Considering that the "Enterprise Internal Control Guidelines" were fully implemented in 2014, this paper selects A-share listed companies with restated financial reports from the main boards of Shanghai and Shenzhen during 2014 to 2016, excluding financial companies and companies with incomplete data. The data are from RESSET database and DIB database.

\section{B. Variables Definition}

The explained variable in this paper is the selective disclosure of internal control deficiencies, and explanatory variables are audit characteristics such as audit scale, audit change, audit tenure and audit opinions of financial reports. When studying the relationship of explanatory variables and explained variables, some control variables should be held constant: corporate size, current ratio, growth, number of supervisors [12].The definition and description of the above variables are shown in Table 1 .

TABLE I VARIABLE DEFINITION AND DESCRIPTION

\begin{tabular}{c|c|c|c}
\hline $\begin{array}{c}\text { Type of } \\
\text { variable }\end{array}$ & Name of variable & $\begin{array}{c}\text { Symbol of } \\
\text { variable }\end{array}$ & Description of variable \\
\hline \multirow{2}{*}{$\begin{array}{c}\text { Explained } \\
\text { variable }\end{array}$} & $\begin{array}{c}\text { Selective } \\
\text { disclosure }\end{array}$ & SD & $\begin{array}{c}\text { If the company disclose no deficiencies in self-evaluation report, the value is 3; } \\
\text { disclose general deficiencies, the value is 2; disclose important deficiencies, the } \\
\text { value is 1; disclose material deficiencies, the value is 0. }\end{array}$ \\
\hline \multirow{4}{*}{$\begin{array}{c}\text { Explanatory } \\
\text { variable }\end{array}$} & Audit scale & AS & If the company employs the top 10 accounting firms in China, the value is 1, \\
otherwise 0.
\end{tabular}

\section{Research Model}

To verify these assumptions, the following model is established:

$$
\mathrm{SD}=\alpha+\beta_{1} \mathrm{AS}+\beta_{2} \mathrm{AC}+\beta_{3} \mathrm{AT}+\beta_{4} \mathrm{AO}+\beta_{5} \mathrm{SIZE}+\beta_{6}
$$
$\mathrm{CUR}+\beta_{7} \mathrm{GRO}+\beta_{8} \mathrm{SUPSIZE}+\varepsilon$

Where: $\alpha$ is a constant value, $\beta 1, \beta 2, \beta 3$ and $\beta 4$ are coefficients of each explanatory variable, $\beta 5, \beta 6, \beta 7$ and $\beta 8$ are coefficients of each control variable, and $\varepsilon$ represent the random error term.

\section{EMPIRICAL ANALYSIS}

\section{A. Descriptive Statistics}

As can be seen from the descriptive statistics of variables in Table 2, among the 398 sample data, the maximum value of selective disclosure is 3 and the minimum value is 0 , the average value is 2.73 , which means that the sample companies have a high degree of selective disclosure in internal control deficiencies. The average value of accounting firms hired by sample companies is 0.46 , indicating that about half of sample companies are audited by accounting firms with good qualifications. The proportion of companies with firm change is $13 \%$, which indicates that the sample companies have stable employment in accounting firms. The audit tenure of accounting firms ranges from 1 to 30 years, with an average of 8.93 years, indicating that most accounting firms have long tenure. The average audit opinion is 0.1 , which means about $10 \%$ of companies' financial reports are issued with non-standard audit opinion. 
TABLE II

DESCRIPTIVE STATISTICS

\begin{tabular}{|c|c|c|c|c|c|}
\hline & $\mathrm{N}$ & Min & Max & Mean & $\begin{array}{c}\text { Std. } \\
\text { Deviation }\end{array}$ \\
\hline SD & 398 & .00 & 3.00 & 2.7387 & .62851 \\
\hline AS & 398 & 0 & 1 & .46 & .499 \\
\hline $\mathrm{AC}$ & 398 & 0 & 1 & .13 & .340 \\
\hline AT & 398 & 1 & 30 & 8.93 & 6.568 \\
\hline $\mathrm{AO}$ & 398 & 0 & 1 & .10 & .304 \\
\hline SIZE & 398 & 17.39 & 25.68 & 22.2561 & 1.40357 \\
\hline CUR & 398 & .04 & 68.97 & 1.9529 & 4.05472 \\
\hline GRO & 398 & -90.76 & 2930.57 & 24.6725 & 176.0014 \\
\hline SUPSIZE & 398 & 1 & 14 & 5.71 & 2.384 \\
\hline Valid N & 398 & & & & \\
\hline
\end{tabular}

\section{B. Correlation Analysis}

Table 3 shows the correlation analysis of the variables. It can be seen that audit scale (AS), audit change(AC) and audit opinion(AO) are significantly negatively correlated with selective disclosure(SD) at the level of $1 \%$, so hypothesis 1,2 , and 4 are tentatively verified. In addition, the company size (SIZE) is positively correlated with selective disclosure (SD) at the level of 5\%, while supervisor size (SUPSIZE) is negatively correlated with selective disclosure (SD) at the level of $1 \%$.The highest correlation coefficient is between audit tenure (AT) and audit change (AC) of -0.474 , where the absolute value is still below 0.65. (Generally speaking, if the absolute value of correlation coefficient between variables is less than 0.65 , it can be considered that variables are independent.) Thus, it can be concluded that in this research model there is no multicollinearity problem.

TABLE III CORRELATION TEST OF VARIABLES

\begin{tabular}{|c|c|c|c|c|c|c|c|c|c|}
\hline & SD & AS & $\mathrm{AC}$ & AT & $\mathrm{AO}$ & SIZE & CUR & GRO & SUPSIZE \\
\hline SD & 1 & $-.150^{* *}$ & $-.155^{\text {** }}$ & -.020 & $-.149^{* *}$ & $.116^{*}$ & .067 & .053 & $-.134^{* *}$ \\
\hline AS & $-.150^{* * *}$ & 1 & .080 & .033 & .016 & -.074 & -.069 & .060 & -.022 \\
\hline $\mathrm{AC}$ & $-.155^{* *}$ & .080 & 1 & $-.474^{* * *}$ & $.208^{* * *}$ & $-.100^{*}$ & .039 & .088 & .017 \\
\hline AT & -.020 & .033 & $-.474^{* * *}$ & 1 & $-.131^{* *}$ & .062 & -.070 & -.022 & -.024 \\
\hline $\mathrm{AO}$ & $-.149^{* *}$ & .016 & $.208^{* * *}$ & $-.131^{* *}$ & 1 & $-.210^{* * *}$ & -.040 & -.053 & $-.104^{*}$ \\
\hline SIZE & $.116^{*}$ & -.074 & $-.100^{*}$ & .062 & $-.210^{* * *}$ & 1 & -.073 & -.065 & .064 \\
\hline CUR & .067 & -.069 & .039 & -.070 & -.040 & -.073 & 1 & .066 & -.035 \\
\hline GRO & .053 & .060 & .088 & -.022 & -.053 & -.065 & .066 & 1 & -.056 \\
\hline SUPSIZE & $-.134^{* * *}$ & -.022 & .017 & -.024 & $-.104^{*}$ & .064 & -.035 & -.056 & 1 \\
\hline
\end{tabular}

Note: ** represents significance of $1 \%$ ( 2-tailed), * represents significance of $5 \%$ ( 2-tailed).

\section{Regression Analysis}

1) Simultaneous Test (F Test). The simultaneous test ( $\mathrm{F}$ Test) is done to see how significant the influence of all explanatory variables on the explained variable simultaneously. The results of $\mathrm{F}$ test are shown in Table 4 below. $\mathrm{F}$ statistical value is 5.540 and $\mathrm{P}$ value of significance test of the equation is 0.000 , which means that the regression effect was good and the regression model was statistically significant.

TABLE IV Simultaneous Test (F TEST)

ANOVA $^{\mathrm{a}}$

\begin{tabular}{c|c|c|c|c|c|c}
\hline \multicolumn{2}{c|}{ Model } & Sum of Squares & Df & Mean Square & F & Sig. \\
\hline \multirow{4}{*}{1} & Regression & 16.040 & 8 & 2.005 & 5.540 & $.000^{\mathrm{b}}$ \\
\cline { 2 - 7 } & Residual & 140.784 & 389 & .362 & & \\
\cline { 2 - 7 } & Total & 156.824 & 397 & & & \\
\hline
\end{tabular}

a. Explained Variable: Selective disclosure

b. Predictors: (Constant), Audit scale, Audit change, Audit tenure, Audit opinion, Company size, Current ratio ,Growth, Supervisor size

2) Partial Test (T test). Partial test (T test) is done to see how strong the influence of each explanatory variable on explained variable. The results of $\mathrm{T}$ test are shown in Table 5 below:
Audit size (AS) is negatively correlated with selective disclosure (SD) at the level of $1 \%(\beta=-0.127, \mathrm{P}=0.009)$, it indicates that companies with large audit scale are subject to stricter supervision and are more inclined to disclose internal 
control deficiencies, so hypothesis 1 is proved.

Audit change $(\mathrm{AC})$ is negatively correlated with selective disclosure (SD) at the level of $1 \%(\beta=-0.172, \mathrm{P}=0.002)$, it indicates that the change of accounting firm promotes the disclosure of internal control deficiencies, so hypothesis 2 is proved.

Audit change $(\mathrm{AC})$ is negatively correlated with selective disclosure (SD) at the level of $5 \%(\beta=-0.117, \mathrm{P}=0.033)$, it indicates that the longer the tenure of accounting firms, the more understanding of the real situation of the company's internal control, so as to inhibit the selective disclosure of internal control deficiencies, so hypothesis 3 is proved.

Audit opinion (AO) is negatively correlated with selective disclosure(SD) at the level of $5 \%(\beta=-0.118, \mathrm{P}=$ 0.020 ), it indicates that listed companies that are issued with non-standard audit opinions are more active in disclosing internal control deficiencies, so hypothesis 4 is proved.

Company size (SIZE) is positively correlated with selective disclosure (SD) at the level of $10 \%(\beta=0.089$, $\mathrm{P}=0.075)$, and Supervisor size(SUPSIZE) is negatively correlated with selective disclosure(SD) at the level of $1 \%(\beta=$ $-0.149, \mathrm{P}=0.002)$. That means the larger the size of the enterprise, the fewer the number of the board of supervisors, the higher the possibility of selective disclosure of internal control deficiencies.

TABLE V RESULT OF T-TEST

Coefficients

\begin{tabular}{|c|c|c|c|c|c|c|}
\hline & \multirow{2}{*}{ Model } & \multicolumn{2}{|c|}{ Unstandardized Coefficients } & \multirow{2}{*}{$\frac{\text { Standardized Coefficients }}{\text { Beta }}$} & \multirow{2}{*}{$\mathbf{t}$} & \multirow{2}{*}{ Sig. } \\
\hline & & B & Std. Error & & & \\
\hline \multirow{9}{*}{1} & (Constant) & 2.302 & .508 & & 4.528 & .000 \\
\hline & SD & -.160 & .061 & -.127 & -2.617 & .009 \\
\hline & AS & -.317 & .103 & -.172 & -3.067 & .002 \\
\hline & $\mathrm{AC}$ & -.011 & .005 & -.117 & -2.138 & .033 \\
\hline & AT & -.244 & .105 & -.118 & -2.329 & .020 \\
\hline & $\mathrm{AO}$ & .040 & .022 & .089 & 1.785 & .075 \\
\hline & SIZE & .008 & .008 & .049 & .999 & .318 \\
\hline & CUR & .000 & .000 & .061 & 1.249 & .213 \\
\hline & GRO & -.039 & .013 & -.149 & -3.075 & .002 \\
\hline
\end{tabular}

a. Explained Variable: Selective Disclosure

\section{CONCLUSIONS AND RECOMMENDATIONS}

Based on the A-share listed companies during the 2014-2016 on the main board of Shanghai and Shenzhen that have been restated in the financial reports, this paper studies the relationship between external audit characteristics and selective disclosure of internal control deficiencies from the perspective of managers' opportunistic behavior. It is found that the external audit characteristics have a significant impact on the selective disclosure of internal control deficiencies. Among them, the larger the size of accounting firm, the more cautious the managers are in the selective disclosure of internal control deficiencies; the replacement of accounting firm can inhibit the selective disclosure of internal control deficiencies; the longer the audit term, the less possibility of selective disclosure. At the same time, the listed companies whose financial reports are issued with non-standard audit opinions have more comprehensive disclosure of internal control deficiencies. In addition, the study also finds that large companies have a higher probability of selective disclosure of internal control deficiencies, and the board of supervisors can effectively suppress the selective disclosure of internal control deficiencies.

The research shows that in the disclosure of internal control deficiencies, external audit can supervise the opportunistic behavior of the manager. The board of supervisors, as an internal governance institution, can suppress the selective disclosure of internal control deficiencies to a certain extent.
Therefore, the regulator should give full play to the role of external audit supervision in improving the disclosure of internal control deficiencies, especially pay attention to the listed companies with small audit scale and short audit tenure.

\section{REFERENCES}

[1] Jiangbo $\mathrm{Xu}$, Xiaodan He. Failure to discover or motivation choice? Causes of internal control deficiencies disclosure dilemma [J]. Research on economics and management, 2016(3):123-130

[2] Yao Zhang, Xuemeng Guo, Xu Xiao. Motivation selection and economic consequences of internal control deficiencies information disclosure [J]. Economic issues, 2016(5):118-123

[3] Krishnan,J.Audit Committee Quality and Internal Control: an Empirical Analysis [J].The Accounting Review.2005,80:649-675.

[4] Xiaolin Chen, Yutao Wang, Yunsen Chen. Firm size, auditing industry expertise and informed transaction probability $[\mathrm{J}]$. Accounting research, 2013(02):69-77+95

[5] Ashbaugh-Skaife, H., D.W.Collins, and W.R.Kinney.The discovery and reporting of internal control deficiencies prior to SOX-mandated audits [J].Journal of Accounting and Economics,2007,44:166-192.

[6] Ettredge M, Heintz J, Li C,et al.Auditor Realignments Accompanying Implementation of SOX 404 ICFR Reporting Requirements[J].Accounting Horizons,2011,25(1):17-39.

[7] Xiaoke Cheng, Haoyang Li, Lidong Zhe. Impact of firm size and audit tenure on disclosure of internal control deficiencies of listed companies -- empirical evidence from integrated audit companies $[\mathrm{J}]$. Systems engineering, 2016, 34(08):1-12. 
[8] Jenkins D S, Velury U. Does auditor tenure influence the reporting of conservative earnings? [J].Journal of Accounting and Public Policy,2008,27(2):115-132.

[9] Baixing Li, Ruijing Li. Disclosure of internal control deficiencies, quality of financial reports and market response [J]. Journal of finance and accounting, 2016(08):10-14.

[10] Yating Lu. Internal control self-evaluation, financial restatements and internal control audit opinion [J]. Friends of accounting, 2016(14):119-122.

[11] Zhenyi Wang, Xi Chen, Hanhan Tang. Disclosure of major deficiencies in internal control, internal control audit and debt financing costs -empirical evidence from A-share financial restatements companies [J]. Friends of accounting, 2018(13):103-107.

[12] Lu Li. Internal control deficiencies, corporate governance structure and financial distress [J]. Finance and accounting communications, 2018(3):103-107. 